\title{
Sensitivity of the overturning circulation of the Baltic Sea to climate change, a numerical experiment
}

\author{
Robinson Hordoir $^{1} \cdot$ Anders Höglund $^{1} \cdot$ Per Pemberton $^{1} \cdot$ Semjon Schimanke $^{1}$
}

Received: 29 August 2016 / Accepted: 20 April 2017 / Published online: 26 April 2017

(C) The Author(s) 2017. This article is an open access publication

\begin{abstract}
An ocean model covering the Baltic Sea area is forced by several climate scenarios for a period extending from 1961 to 2100 . The Baltic Sea overturning circulation is then analyzed. The analysis shows that this circulation decreases between the end of the 20th century and the end of the 21st century, and that the decrease is amplified in the case of the strongest greenhouse gas emission scenarios, which corresponds with the highest warming cases. The reasons behind this decrease in overturning circulation are investigated. A strong increase of thermal stratification is noticed at the level of the Baltic Sea mixed layer. Based on buoyancy flux considerations, we demonstrate that the decrease in overturning circulation coincides with the increase of thermal stratification. Evidence shows that the underlying process is linked to a smaller erosion of the halocline due to a higher shielding, itself linked with a stronger and longer seasonal thermocline. This theory works if surface wind mixing is not taken into account directly in the computation of buoyancy fluxes.
\end{abstract}

Keywords Baltic Sea $\cdot$ Climate change $\cdot$ Overturning circulation $\cdot$ Thermal stratification

\section{Introduction}

The Baltic Sea is a marginal sea in Central/Northern Europe which presents an interesting mixture of different dynamics. The amount of river runoff delivered to the Baltic Sea, and its narrow connection to the North Sea through

Robinson Hordoir

robinson.hordoir@smhi.se

1 SMHI, 60176 Norrköping, Sweden the Danish Straits give the Baltic Sea typical sill estuarine dynamics. Although many dynamical features of the Baltic Sea are geostrophic, due to its size, it is still an estuary. As for any estuarine structure, the amount of freshwater delivered to the estuary generates an overturning circulation in the same sense as that described by Garvine and Whitney (2006). This means that the delivery of freshwater can be considered as a delivery of vorticity or energy (Hordoir et al. 2008). For this reason, one can define an overturning circulation in the Baltic Sea (Döös et al. 2004), which is much larger than the amount of runoff delivered to the estuary or coastal area. Of course any estuarine or freshwater driven circulation is influenced by many parameters, the most important ones being wind forcing (Fong and Geyer 2002; Hordoir et al. 2006) and tidal currents (Hordoir et al. 2006). In the case of the Baltic Sea, tides are negligible but wind forcing does play an important role in its overturning circulation. Wind forcing over the Baltic and North Seas, and especially wind forcing variability, drive Baltic Sea salt inflows and so-called "Major Baltic Inflows" (MBI hereafter) (Matthäus 2006). MBIs are the drivers of the haline conveyor belt defined by Döös et al. (2004). MBIs are spurious phenomena of which the haline conveyor belt is the long-term result, MBIs and the haline conveyor belt in the Baltic Sea are two different visions of the same thing.

Many questions have arisen during the recent decades as the number of MBIs has decreased. After a stagnation period from 1983 to 1993 , several MBIs have occurred but their frequency has been lower than during the 1960s and 1970s. Then MBIs occurred during three consecutive years $(2014,2015$ and 2016), but it is yet too early to say if this latest series is part of a longer trend. The future of Baltic inflows is a subject of importance, and several studies have tried to identify whether changes of wind patterns related with a changing climate could be responsible for 
their decrease. Lately, one can cite (Schimanke et al. 2014) who used a EOF decomposition of atmospheric pressure over Northern Europe to identify the atmospheric patterns that create MBIs. Based on this decomposition and using five different climate scenarios (Samuelsson et al. 2011), they have forecasted an increase of MBIs in the Baltic Sea towards the end of the 21st century. However, their study was only based on atmospheric patterns and did not include an ocean model. The Baltic Sea has complex reactions to changes in atmospheric patterns, such as changes in salinity, temperature or mixing, which affect its baroclinic dynamics. Thus, it is difficult to forecast if the number of MBIs will indeed increase. MBIs have for example a negative feedback on themselves: a too high salinity of the lower Baltic layers is a blocking factor. An increase of extreme wind strength is also a factor that influences vertical mixing, which is also a negative factor affecting MBIs and deep salinity (Meier 2005). However, the values of wind speed increase mentioned in Meier (2005) are far beyond the increases observed in our climate scenarios.

The purpose of this article is to provide a broader answer in terms of changes in the MBI process by combining the latest climate scenarios used by Schimanke et al. (2014) with the use of a Baltic Sea ocean model. In particular, we aim to understand what are the effect of changes in direct atmospheric forcing (wind forcing, temperature) on the Baltic Sea thermo-haline structure and how these changes affect the baroclinic circulation. Section 2 explains the methodology we use from a modeling point of view and how we analyzed these results. Results are presented in Sects. 3 and 4 we provide the analysis of the results and provide a theoretical relation between changes in climate change and changes in the overturning circulation in the Baltic Sea. A final section concludes this article.

\section{Methodology}

\subsection{Ocean modeling strategy}

We use the Nemo-Nordic configuration (Hordoir et al. 2013, 2015) in its most recent version, based on Nemo 3.6 (Madec 2015). Nemo-Nordic is a Nemo based ocean model for Baltic and North Seas that is able to reproduce the long term variability of the Baltic Sea haline structure (Hordoir et al. 2015). In addition, Nemo-Nordic abilities in reproducing the sea level and ice cover of Baltic and North Seas in operational mode have been asserted, and Nemo-Nordic is now SMHI's (Swedish Meteorological and Hydrological Institute) new forecast model in replacement of HIROMB (Funkquist and Kleine 2007).

In the present article, we use a restricted domain of Nemo-Nordic that includes only the Baltic Sea and the
Kattegat region located between Denmark and Sweden. This restricted domain is chosen in order to save computing time as the purpose of this study is to focus on long term evolution of the Baltic Sea over time scales of almost 140 years. This restricted configuration has one open boundary along a zonal axis located between South of Skagen (Northern tip of Denmark) and Gothenburg (Swedish West Coast).

The vertical and horizontal grids of this Baltic only configuration are strictly identical to that of Nemo-Nordic, the only difference being that it has a restricted domain and a simplified open boundary condition. At this open boundary condition, sea level is imposed as well as temperature and salinity.

We set in total four simulations using the same atmospheric forcing that are used by Schimanke et al. (2014). Based on two global climate models (EC-EARTH and MPI) driving the RCA4 atmospheric configuration (Samuelsson et al. 2011), we have access to the simulated atmospheric circulation for the control period (1961-2005), and for two emission scenarios (RCP 4.5 and RCP 8.5 ) for the period 2005-2100.

All simulations start in 1961 from a rest state and with temperature and salinity fields taken from a climatology. Table 1 summarizes the simulations.

One crucial element to ensure a consistent haline circulation in the Baltic Sea is to set a proper sea level and sea level variability at the open boundary. We use the same method as described in Meier et al. (2012) to compute the sea level at the open boundary, using the atmospheric pressure simulated by RCA4 driven by an ERA-40 reanalysis on one side, and the sea level measurements at a tide gauge located in Gothenburg on the other. Just as in Meier et al. (2012), tides are neglected since they do not account for any significant contribution in the long term exchange between Baltic and North Seas. And as in Meier et al. (2012), temperature and salinity are set to climatological values: the exchange with the atmosphere between the open boundary condition and the Baltic Sea entrance is enough to ensure that water entering the Baltic Sea has a temperature trend that follows that of the atmospheric forcing. Runoff changes can dramatically affect the haline structure of the Baltic Sea (Meier et al. 2006), but in this set of experiments we want to concentrate on the Baltic Sea response to changes in atmospheric forcing. Therefore we use a climatological runoff and focus our research on the understanding of the changes in baroclinic circulation in the Baltic Sea related with the direct changes in atmospheric forcing.

\subsection{Analysis protocol}

The work done by Schimanke et al. (2014) identified atmospheric patterns related with MBIs. In their study, 
they used observed salinities following the protocol defined by Matthäus (2006) in order to identify MBIs. Matthäus (2006) defined three criteria in order to identify an ongoing MBI based on Darss Sill salinity: The deep salinity at Darss Sill should be at least 17 PSU, with a low stratification, and last at least 5 days. However, this set of criteria is not easily transferable to an ocean model. Applying them to a hindcast simulation of Nemo-Nordic that has a good representation of the Baltic Sea deep salinity does not permit to identify many MBIs during the hindcast period used in Hordoir et al. (2015).

Modifying the criteria by either moving the observational point or the reference salinity (17 PSU) makes the criteria either over-sensitive to any inflow occurring in the ocean model, or on the contrary does not permit to identify many MBIs. Another solution in order to identify MBIs can be to analyze the deep salinity of the Baltic Sea at a station such as BY15 (Gotland Deep) which is often taken as a reference for its good representation of the mean Baltic Sea haline structure both in terms of salinity and stratification. But this strategy does not work either. First because there exists no criteria on how to identify a MBI based on deep Baltic Salinity. Second because even if there was such a criteria, as for the criteria defined for the Darss Sill by Matthäus (2006), applying measurement based criteria to a model does not take into account the inevitable biases of the model. A last method could have consisted in trying to measure the volume and salt flow variability to try to relate it to MBI occurency, but this method proved to be too sensitive to the salinity biases of the model as well. The definition of an MBI or of any Baltic Sea salt inflow is a very empirical concept, mostly based on observations, which makes it difficult to apply to an ocean model, especially when its resolution is rather low compared with the horizontal and vertical dimensions of the Danish Straits as it is the case in this study.

For these reasons we distance our analysis strategy from that taken by Matthäus (2006) or Schimanke et al. (2014): instead of analyzing MBIs, or any salt inflow that reaches the lower layers of the Baltic Sea, as discrete or quantified phenomena, we perform our analysis on the resulting circulation which is directly driven by MBIs, that is the Baltic Sea haline conveyor belt as defined by Döös et al. (2004).

\subsubsection{Meridional flux function}

Döös et al. (2004) define a meridional stream function in the Baltic Sea, which can be viewed along meridional and depth axis. We adopt a similar strategy but also use a meridional transport function. Figure 2 shows the meridional transport from the latitude of the Southern tip of Sweden towards the North of the Bothnian Bay. The Meridional Transport is computed by integrating meridional transport (in $\mathrm{m}^{3} \mathrm{~s}^{-1}$ ) along the zonal axis, for every model grid cell of the integration box shown on Fig. 1, according to the following equation:

$F(y, z)=\frac{1}{\lambda_{\max }-\lambda_{\min }} \int_{\lambda_{\min }}^{\lambda_{\max }} q(\lambda, y, z) d \lambda$

in which $\lambda$ is the longitude, with $\lambda_{\min }$ and $\lambda_{\max }$ being respectively the minimum and maximum values of $\lambda$ along which integration is done. $q(\lambda, y, z)$ is the meridional transport (in $\mathrm{m}^{3} \mathrm{~s}^{-1}$ ) at longitude $\lambda$ and at position $y$ (in nautical miles) along the latitude axis, and at depth $z$.

If computed based over a time period long enough to low-pass filter wind variability, $F(y, z)$ gives a representation of the overturning circulation of the Baltic Sea. $F(y, z)$ is positive from the bottom up to a level of about $30-40 \mathrm{~m}$ which is higher than that of the Baltic Sea pycnocline. Above this level, $F(y, z)$ is negative, reflecting the overturning circulation of the Baltic Sea.

The vertical variations of $F(y, z)$ are not only related with the transport, but also with the vertical resolution of the model. However, this does not affect the sign of the transport. In addition, we are interested in the variations of $F(y, z)$ between present and future climate more than in its value.

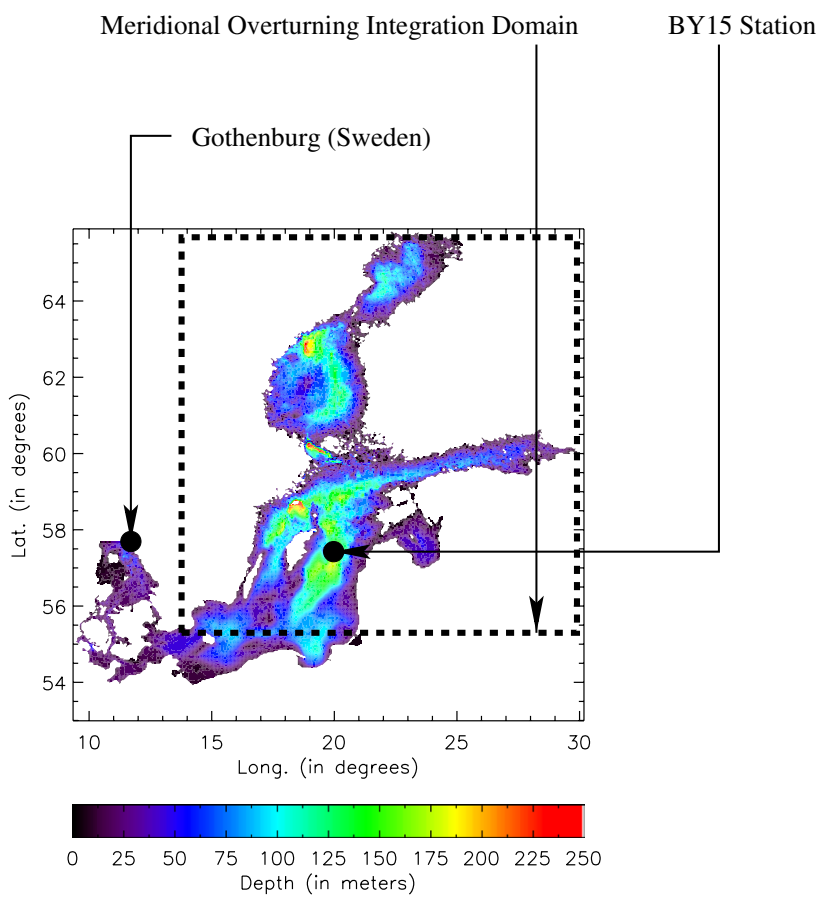

Fig. 1 Domain and bathymetry for the restricted Nemo-Nordic configuration used in the present study. The position of Gothenburg is shown as it is where the open boundary condition is located. The Gotland Deep (BY15) measurement station location is also shown 
Table 1 Summary of simulations

\begin{tabular}{lll}
\hline Period and scenario/driving GCM & EC-Earth & MPI \\
\hline 1961-2005 & EC-H & MPI-H \\
$2006-2100$ RCP 4.5 & EC-4.5 & MPI-4.5 \\
2006-2100 RCP 8.5 & EC-8.5 & MPI-8.5 \\
\hline
\end{tabular}

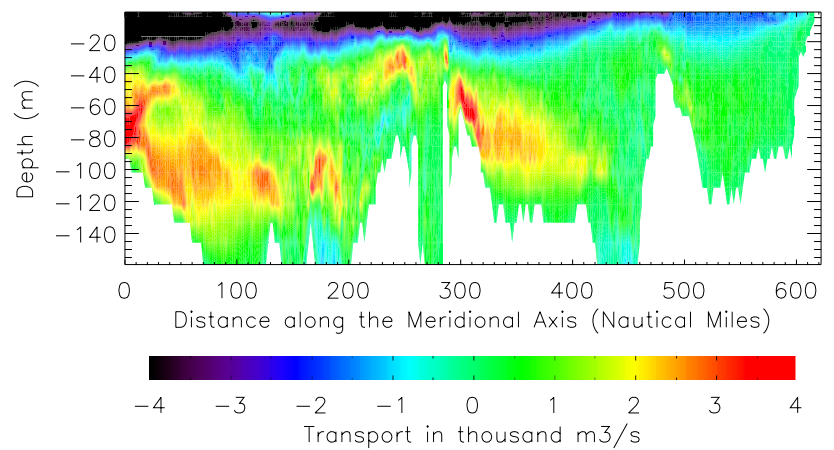

Fig. 2 Transport function $F(y, z)$ (in $\mathrm{m}^{3} \mathrm{~s}^{-1}$ ), along the meridional axis of the Baltic Sea. Average value from 1975 to 2005 computed from the EC-H simulation. The values of transport in the color scale are bounded from -4000 to $4000 \mathrm{~m}^{3} \mathrm{~s}^{-1}$ but can exceed these values

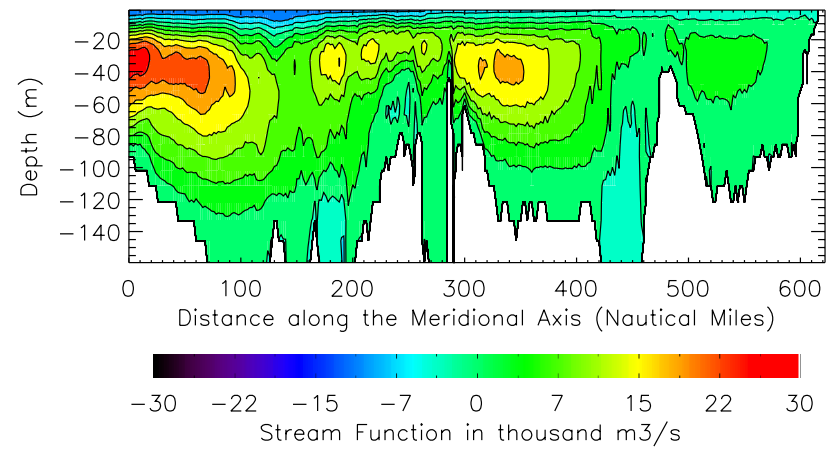

Fig. 3 Stream function $M_{s t}\left(y, z\right.$ ) (in $\mathrm{m}^{3} \mathrm{~s}^{-1}$ ), along the meridional axis of the Baltic Sea. Average value from 1975 to 2005 computed from the EC-H simulation

Based on $F(y, z)$, one can also compute a meridional stream function in the same manner as Döös et al. (2004) by depth integration from the bottom towards the surface:

$M_{s t}(y, z)=\frac{1}{H(y)-z} \int_{H(y)}^{z} F\left(y, z^{\prime}\right) d z^{\prime}$

Based on the same simulation as for Fig. 2, Fig. 3 shows the meridional stream function $M_{s t}(y, z)$.

Figure 3 shows that there are four overturning cells from the Southern tip of Sweden towards the coast of the Bothnian Bay. From left towards right, the first cell corresponds

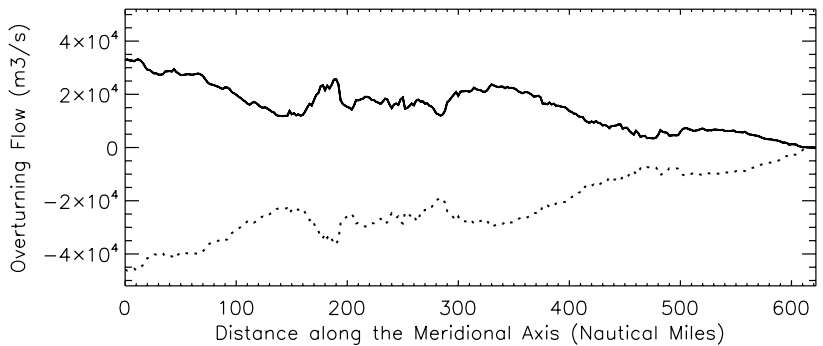

Fig. 4 Baltic overturning (solid line) extracted from the period 1975-2005 from the EC-H simulation (Table 1), and total resulting circulation eventually leaving the Baltic Sea (dashed line)

to the main Baltic Sea overturning circulation and ends approximately 30 nautical miles North of the latitude of Gotland Deep (BY15).

\subsubsection{Overturning circulation computation}

In the same manner as for the computation of function $F(y, z)$ defined in Sect. 2.2.1, we can compute the Baltic Sea Overturning. The Baltic Sea Overturning is the circulation which is generated by the input of vorticity through runoff combined with wind to the Baltic Sea, but which is not runoff. For any latitude, the value of this Baltic Sea Overturning $F_{o}(y)$ is therefore simply the total positive circulation:

$F_{o}(y)=\int_{-H(y)}^{0} \int_{\lambda_{\min }}^{\lambda_{\max }} q^{o}(\lambda, y, z) d \lambda d z$

with

$q^{o}(\lambda, y, z)=q(\lambda, y, z) \quad$ if $q(\lambda, y, z) \geq 0$

$q^{o}(\lambda, y, z)=0 \quad$ if $q(\lambda, y, z)<0$

In the same manner, $F_{t}(y)$ which is the total resulting circulation heading towards the exit of the Baltic Sea can be defined as:

$F_{t}(y)=\int_{-H(y)}^{0} \int_{\lambda_{\min }}^{\lambda_{\max }} q^{t}(\lambda, y, z) d \lambda d z$

with

$q^{t}(\lambda, y, z)=q(\lambda, y, z) \quad$ if $q(\lambda, y, z) \leq 0$

$q^{t}(\lambda, y, z)=0 \quad$ if $q(\lambda, y, z)>0$

Figure 4 shows the $F_{o}(y)$ and $F_{t}(y)$ overturning circulation extracted from simulation $\mathrm{EC}-\mathrm{H}$, and the resulting circulation leaving the Baltic Sea (negative dashed line). The symmetry between $F_{o}(y)$ and $F_{t}(y)$ is obvious and the difference of their absolute values reaches around more than 10,000 
$\mathrm{m}^{3} \mathrm{~s}^{-1}$ at the southernmost point, which corresponds to the cumulated amount of runoff released into the Baltic Sea above this latitude. The Baltic Overturning reaches almost $35,000 \mathrm{~m}^{3} \mathrm{~s}^{-1}$ in the Southern Baltic Sea, which is almost triple the value of the cumulated runoff input. The resulting circulation leaving the Southern Baltic is of the order of $45,000 \mathrm{~m}^{3} \mathrm{~s}^{-1}$.

\section{Results}

We can compute the differences in Baltic Sea Overturning circulation by computing the differences in Meridional Transport Function $F(y, z)$ and the differences in $F_{o}(y)$ and $F_{t}(y)$, between a control period that we define from 1975 to 2005, and a future climate period that we extract from 2069 to 2099. We do not use results of the control period located before 1975 in order to avoid spin-up effects inherent to the Nemo-Nordic configuration (Hordoir et al. 2015).

\subsection{EC-Earth simulations}

Figure 5a shows the transport function $F(y, z)$ for the control period of the EC-Earth Simulation. Below Fig. 5b, c show the transport functions between experiments EC-4.5 and EC-8.5 respectively. The pattern of differences is similar for EC-4.5 and EC-8.5 simulations, although it is more intense for the highest emission scenario. The analysis shows a significant decrease of flux at the level of the pycnocline, and to a lower extent of deep salt inflows. Since the ventilation at the level of the pycnocline is the dominant feature in terms of flux (Meier and Kauker 2002), this means basically that the decrease of meridional flux is highest at the vertical level where the meridional flux is itself highest. Further, the decrease in overturning is observable after each entrance to a sub-basin as the flux towards Northern latitudes below $40 \mathrm{~m}$ is decreased. Above $40 \mathrm{~m}$, the value of $F(y, z)$ increases, meaning that the transport heading towards the exit of the Baltic Sea is also lower.

Figure 7 shows the integrated overturning flow difference between simulations EC-4.5/EC-8.5 and the EC-H simulation. The decrease in overturning reaches $4000 \mathrm{~m}^{3}$ $\mathrm{s}^{-1}$ in the Southern Baltic Sea for the RCP 8.5 scenario, which corresponds to a decrease of more than $20 \%$ of the overturning circulation observed during the control period. The decrease in overturning circulation can be observed from South towards North. These results contradict the analysis done by Schimanke et al. (2014) which predicts a relatively important increase of salt inflows, and therefore in overturning circulation, when comparing the
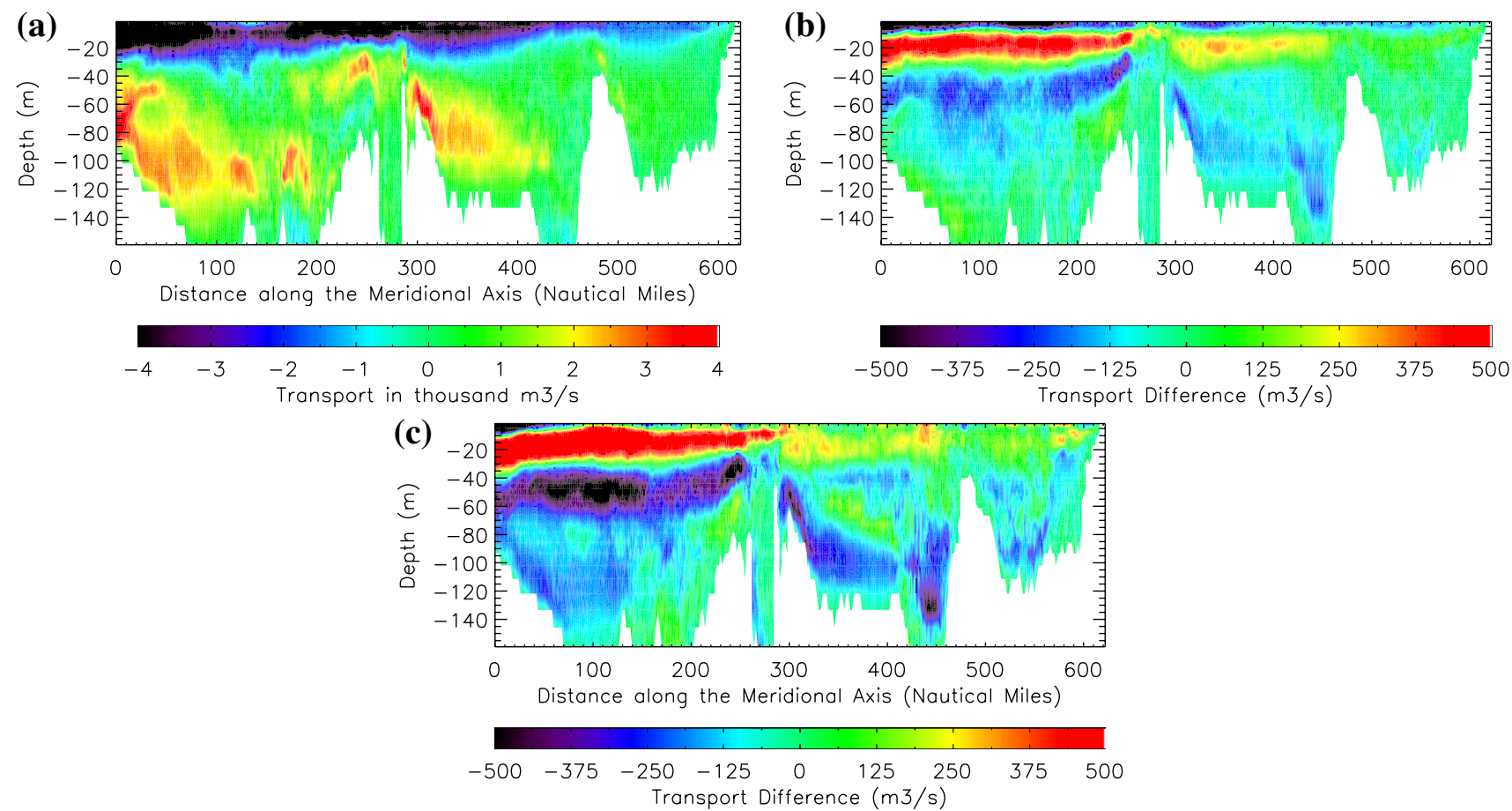

Fig. 5 a Transport function $F(y, z)$ along the meridional axis in the Baltic Sea in EC-H, same as Fig. 2. Average value from 1975 to 2005 computed from an EC-Earth forced simulation. The values of transport are bounded from -4000 to $4000 \mathrm{~m}^{3} \mathrm{~s}^{-1}$ but can exceed these values. b Difference of transport function $F(y, z)$ between EC-4.5 and EC-H. c Difference of transport function $F(y, z)$ between EC-8.5 and EC-H 
atmospheric patterns responsible for MBIs in the EC-Earth simulations, between the control period and the end of the 21st century. The Baltic Sea haline structure is affected by a mean salinity increase of about 0.5 PSU (Fig. 6). The haline stratification is slightly affected with a smoother halocline.

Figure 8 shows the salinity difference profile at BY15 station (Fig. 1), which is located East of Gotland Island. This station located on one of the deepest places of the Baltic Sea is the end of the pathway for salt water inflows. One notices a consistent salinity increase between the control period and the end of the 21 st century, which appears to be surprising if one considers that the overturning circulation, or the probability of MBI occurency, is actually lower.

Figure 8 shows the differences in the mean stratification structure (Brunt-Vaisala Frequency changes) of the Baltic Sea at BY15 station. It shows that the stratification structure of the Baltic Sea central basin (The Baltic Proper) changes between present and future climate. The stratification structure does not change in the deepest part of the Baltic Sea, but diminishes between 35 and $55 \mathrm{~m}$. Above $35 \mathrm{~m}$ there is a strong increase of stratification. Assuming that salinity or temperature changes are small enough to keep the equation of state linear around a point of equilibrium, we also construct the stratification structure assuming that only temperature or salinity changes between present and future climate. Using this approximation permits to show that salinity changes are responsible for the decrease of stratification previously mentioned, and that temperature changes are responsible for the increase of stratification. Salinity and temperature changes are also plotted and show a consistent salinity and temperature increases. However, temperature changes are higher close to the surface than deeper. This result is similar to that obtained by Hordoir and Meier (2011): temperature increase leads to a strong thermal stratification increase in the Baltic Sea, which increases with lower salinities. The increase of stratification observed in the present experiment fits with the values observed by Hordoir and Meier (2011), although they are lower compared with the summer values found by Hordoir and Meier (2011) as the present experiment is a long term mean including all seasons. Alongside the changes in stratification structure, Fig. 8 also shows the meridional transport at the latitude of BY15 and the temperature and salinity changes at BY15. The positive changes in stratification precisely match the area where we see a net increase of negative transport, meaning that the thermal stratification increase coincides with the decrease of the outgoing flux.

\subsection{MPI simulations}

The results of the MPI forced simulations are presented in a similar fashion. Figure 9 shows the transport function for the control period 1975-2005. One can also

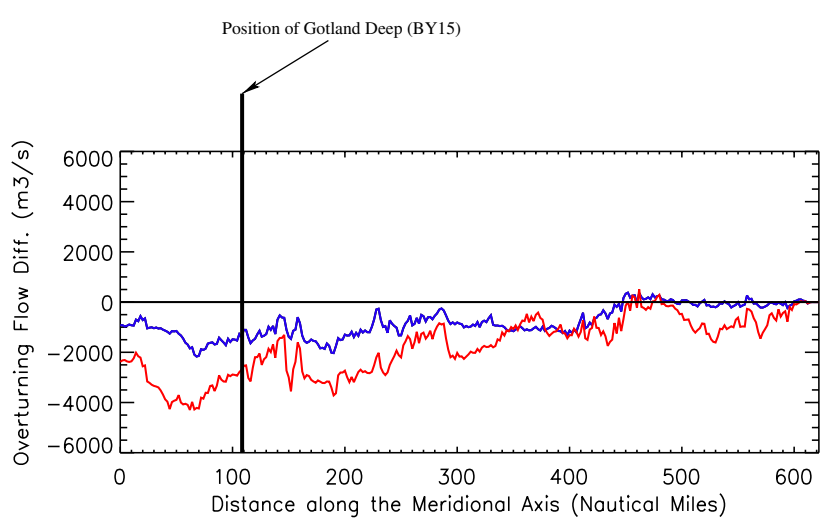

Fig. 7 Difference of overturning circulation, between experiments EC-4.5 and EC-H (blue curve), and between experiments EC-8.5 and EC-H (red curve). The relative difference of overturning circulation is -6.5 and $-15 \%$ for EC-4.5 and EC-8.5 at Gotland Deep (BY15), respectively
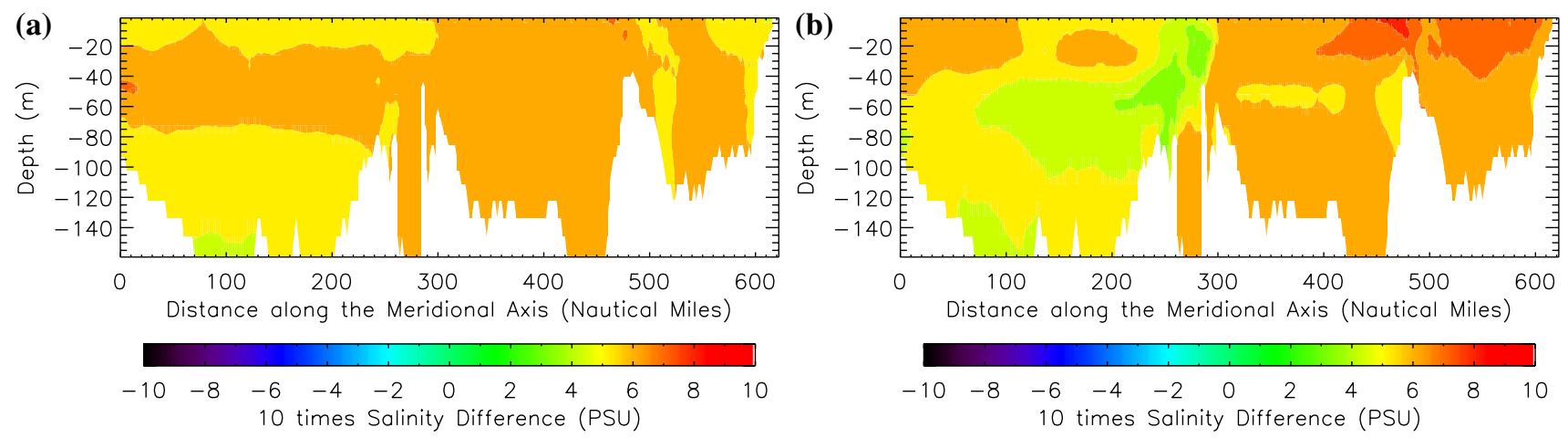

Fig. 6 a Difference of zonally integrated salinity between EC-4.5 and EC-H. b Difference of zonally integrated salinity between EC-8.5 and EC-H 

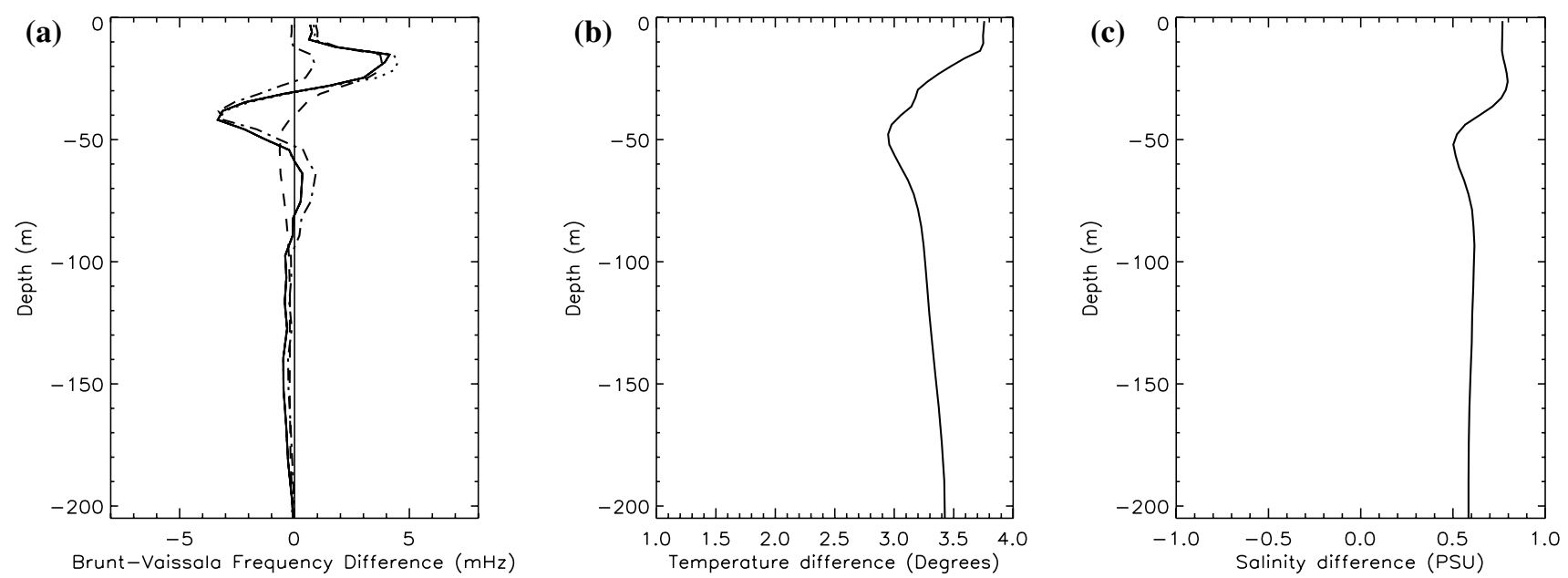

Fig. 8 a Difference of stratification (Brunt-Vaisala frequency, in $\mathrm{mHz}$ ) between EC-8.5 and EC-H at BY15. Plain line stratification difference, computed from the difference of mean stratification between the two times periods. Dotted line stratification difference computed linearly from differences in mean temperature and salinity between the two time periods. Dashed line stratification difference computed from differences in temperature only between the two time periods. Dashed-dotted line stratification difference computed from differences in salinity only between the two time periods. b Temperature difference (in degrees) between EC-8.5 and EC-H time periods. c Salinity difference (in PSU) between EC-8.5 and EC-H time periods
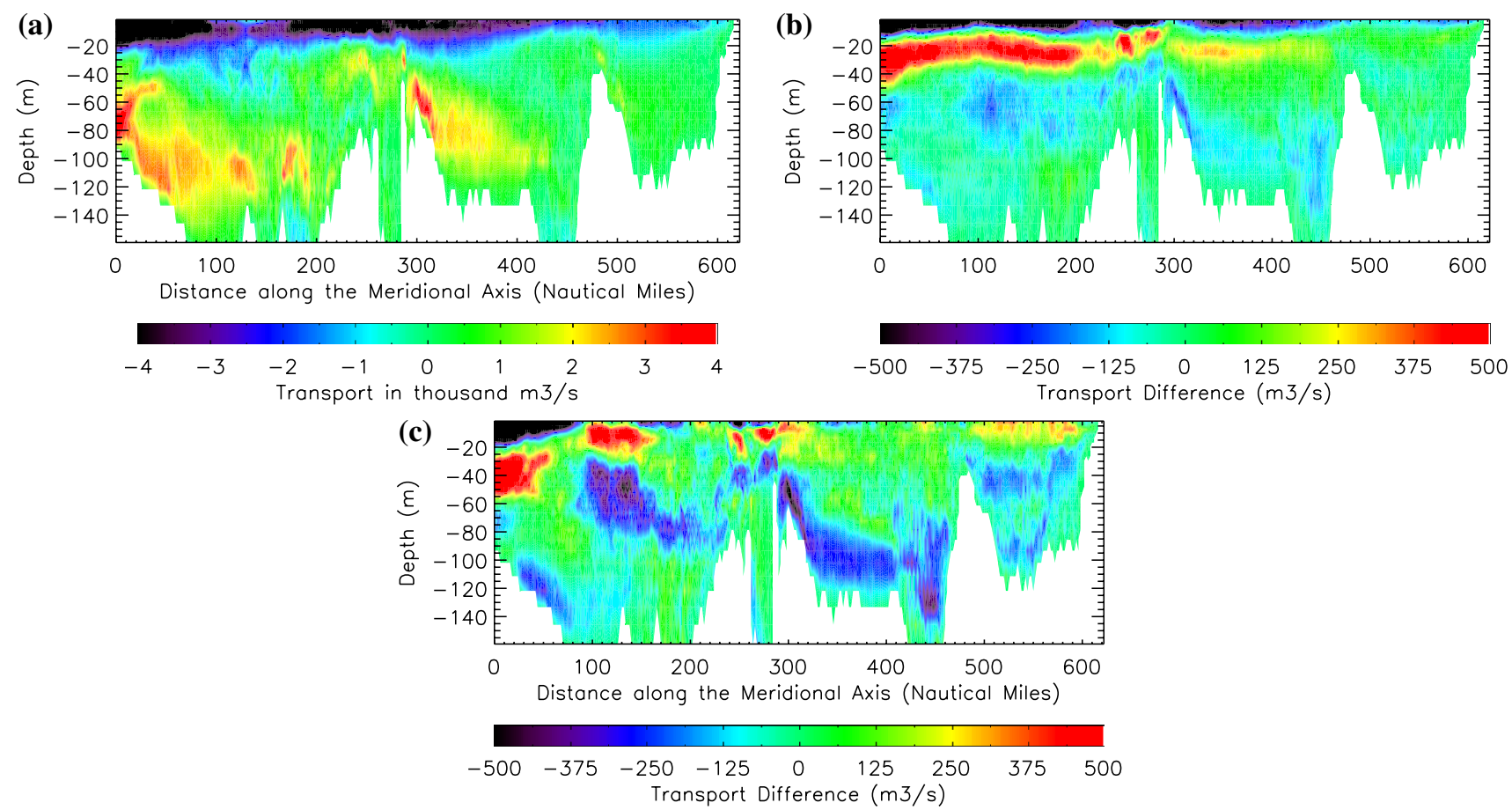

Fig. 9 a Transport function $F(y, z)$ along the meridional axis in the Baltic Sea in MPI-H, same as Fig. 2. Average value from 1975 to 2005 computed from an MPI-Earth forced simulation. The values of transport are bounded from -4000 to $4000 \mathrm{~m}^{3} \mathrm{~s}^{-1}$ but can exceed

notice a decrease of the positive incoming circulation, and an increase of the outcoming negative circulation, which suggests a lower overturning circulation in this set of simulation. The decrease in overturning circulation is these values. b Difference of transport function $F(y, z)$ between MPI4.5 and MPI-H. c Difference of transport function $F(y, z)$ between MPI-8.5 and MPI-H

higher when Nemo-Nordic is forced by a scenario which has a highest greenhouse gas emission (RCP8.5).

The associated changes in overturning circulation are shown in Fig. 11. One can actually notice an increase of 
overturning circulation in the Southern Baltic, which is consistent with the predictions made by Schimanke et al. (2014). However, as one moves further up there is a consistent decrease in overturning circulation in the Baltic Proper. The decrease becomes even higher in the Bothnian Sea and Bothnian Bay, which means that the relative decrease (in percent) for these areas is even higher than in the EC-EARTH forced simulations. The salinity structure is more affected by changes than in the EC-EARTH simulations (Fig. 10), with a moderate decrease of about 0.5 PSU for the MPI-8.5 simulation, but which is not distributed evenly. There is a haline stratification decrease above the level of the halocline in the Northern part of the Baltic Proper.

Changes in the stratification structure can also be observed (Fig. 12). The changes in stratification structure are similar although not identical. Temperature related stratification does increase close to the surface, although it does less, and does not extend as deep as in for the ECEarth forced simulation. An increase in haline stratification also occurs below the level of the halocline, followed by a decrease of haline stratification.

\section{Analysis}

As for the Atlantic Meridional Overturning Circulation (AMOC hereafter), any estuarine circulation is associated with an overturning circulation, and requires mixing between entering saltier water masses, and fresher water masses created by runoff. If estuarine mixing did not occur, then freshwater coming from rivers would just slide over saltier water masses like oil over water without creating any overturning circulation. Tides and internal tidal wave breaking is an essential process to allow water masses to mix and ensure the continuity of the AMOC in convection or upwelling areas. In many estuaries, tidal mixing is less important since the shear between incoming and

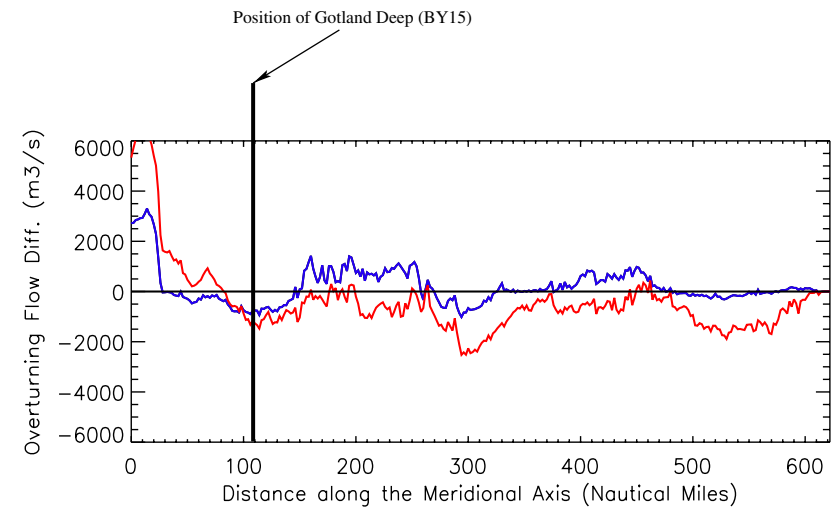

Fig. 11 Difference of overturning circulation between experiments MPI-4.5 and MPI-H (blue curve), and between experiments MPI-8.5 and MPI-H (red curve). The relative difference of overturning circulation is -5 and $-9 \%$ for MPI-4.5 and MPI-8.5 at Gotland Deep (BY15), respectively

outgoing water masses becomes so high at some point that the induced turbulence eventually mixes water masses together and ensures the overturning circulation. However, in the case of deep sill-bounded estuaries such a the Baltic and Black Seas, mixing of lower and upper water masses is a slower process that requires longer time scales and that requires a contact between the base of the thermal mixed layer and the halocline. For the specific case of the Baltic Sea, Stigebrandt (1985) explicitly states that "for a large part of the year the seasonal thermocline shields the main halocline in the Baltic Sea from direct contact with the well mixed surface layer". From a climate change perspective, this means that a change in the physical structure and seasonality of the thermally controlled mixed layer influences the mixing of heavy saltier masses with the mixed layer, controlled by the changes in "entrainment velocity" $w_{e}$ (Stigebrandt 1985) (Eq. 4). When it comes to the Baltic Sea, this mixing occurs independently in different basins as the halocline in the Baltic Proper is located below the level
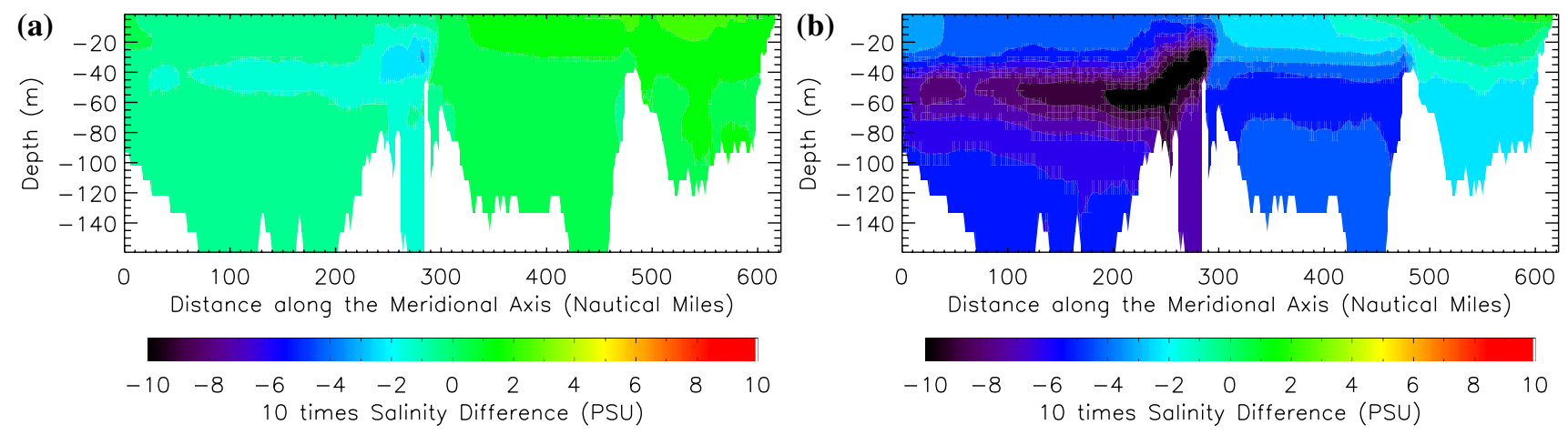

Fig. 10 a Difference of zonally integrated salinity between MPI-4.5 and MPI-H. b Difference of zonally integrated salinity between MPI-8.5 and MPI-H 

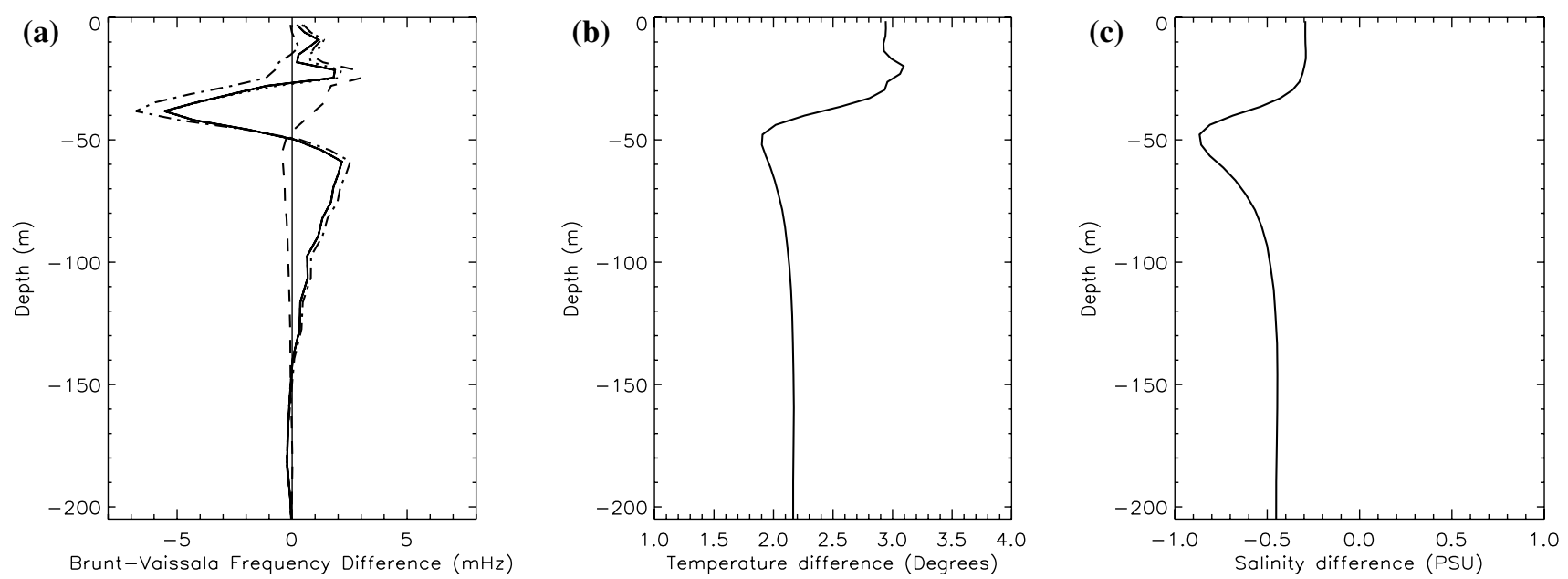

Fig. 12 a Difference of stratification (Brunt-Vaisala frequency, in $\mathrm{mHz}$ ) between MPI-8.5 and MPI-H at BY15. Plain line stratification difference, computed from the difference of mean stratification between the two times periods. Dotted line stratification difference computed linearly from differences in mean temperature and salinity between the two time periods. Dashed line stratification difference

of the sill located at the entrance of the Gulf of Bothnia. The baroclinic circulation of these sub-basins originates and finishes above the level of the Baltic Proper halocline. For the case of the Baltic Proper, the changes in stratification structure at its central point (Gotland Deep BY15, Figs. 8 and 12) exhibit an increase of thermal stratification in both EC-EARTH and MPI forced simulations in the mixed layer. From a haline point of view, there is always a decrease of saline stratification below, and for the case of the MPI forced runs an increase of saline stratification further down. However, changes in haline structure can only increase the salt flux further up either by easing its contact upwards (in the case of the decrease of haline stratification), or not changing the final erosion of the halocline into the surface mixed layer since the increase in haline stratification is below the level of the sharpest halocline, which is precisely the case in our study. Therefore, the new limiting factor of diffusion of saltier water masses towards the surface mixed layer is the increase of thermal stratification between the surface and approximately $35 \mathrm{~m}$. It does not matter if there is a decrease of stratification that accelerates the migration of salt towards the surface at one place if a decrease occurs at another location on the water column, the increase of stratification acts as a bottleneck for the migration of salt from the depths of the Baltic Sea towards the surface.

Based on a balance of wind stress, buoyancy and stratification power fluxes, Stigebrandt (1985) provides a way to estimate the entrainment velocity $w_{e}$, which is detailed below: computed from differences in temperature only between the two time periods. Dashed-dotted line stratification difference computed from differences in salinity only between the two time periods. b Temperature difference (in degrees) between MPI-8.5 and MPI-H time periods. c Salinity difference (in PSU) between MPI-8.5 and MPI-H time periods

$w_{e}=\frac{2 m_{0} u_{*}^{3}}{g h \Delta \rho / \rho}-\frac{B}{g \Delta \rho / \rho}$

in which $m_{0}$ is an empirical constant, $u_{*}$ is the wind friction velocity, $h$ is the thickness of the mixed layer, $\Delta \rho$ is the density gradient between the base of the thermal mixed layer and surface, $\rho$ is a reference density and $g$ is gravity. $B$ is a buoyancy flux that accounts both for thermal and freshwater buoyancy fluxes. $B$ latest can be written as:

$B=g\left(\frac{\alpha}{\rho C_{p}} Q_{\text {in }}-\beta F S\right)$

in which $\alpha$ and $\beta$ are respectively the thermal and haline expansion coefficients in the mixed layer, $C_{p}$ is a heat capacity, $Q_{i n}$ is the incoming heat flux, $F$ is the net freshwater input through the surface, and $S$ is the mixed layer salinity. The friction velocity $u_{*}$ is computed based on the surface stress $\tau$, which is extracted from the model:

$u_{*}=\sqrt{\frac{\tau}{\rho}}$

We have implemented this simple model of the entrainment velocity within the surface mixed layer, by taking Gotland Deep (BY15) as a reference. The net freshwater input comes directly from the simulation. The surface mixed layer density difference is also taken from the model and $h$ is adjusted to the thickness on which one notices an increase of thermal stratification. The entrainment velocity is computed for the entire control period and its mean 
value is taken. The same is done for the 2005-2099 period, during which we compute the annual mean value of the entrainment velocity. In both cases, we do not take into account the heat flux as its mean annual value is supposed to be close to zero, especially when integrated over long time scales.

We compute the relative change of entrainment velocity $w_{e}(y)$ between each year of the 2005-2099 period, in comparison with that of the control period $w_{\text {ref }}$. This is defined as:

$R w(y)=\left(w_{e}(y)-w_{\text {ref }}\right) / w_{\text {ref }}$

Equation 7 uses a ratio of wind stress power and stratification, and this formulation is used for the computation of $R w(y)$. However it is also possible not to take the changes of wind stress power. $R w_{\rho}(y)$ is a function similar to $R w(y)$ where $w_{e}(y)$ is computed using only density changes for the period 2005-2099. Of course, the final stratification structure itself results from a balance between wind power and buoyancy fluxes, so both can not be separated, but the computation of $R w_{\rho}(y)$ allows to see how $R w(y)$ would have evolved if only stratification and buoyancy fluxes had

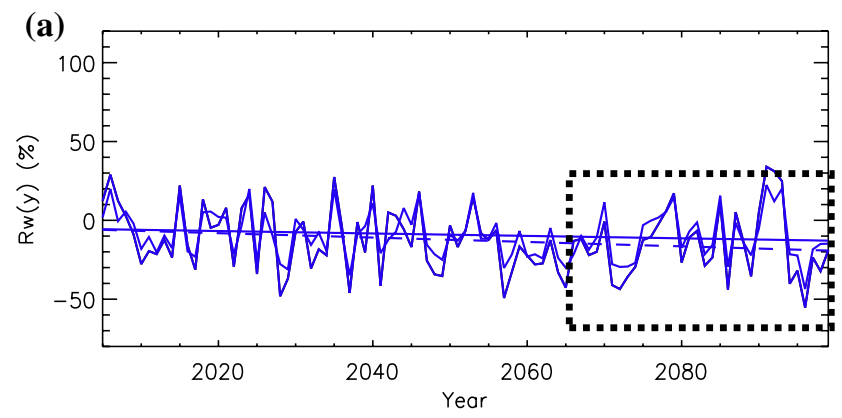

Fig. 13 Functions $R w(y)$ (solid line) and $R w_{\rho}(y)$ (dashed line) plotted with their least squared regressions. a EC-4.5 simulation, the linear variation coefficients of $R w(y)$ and $R w_{\rho}(y)$ are respectively -0.14 and $-0.08 y^{-1}$. The mean values of $R w(y)$ and $R w_{\rho}(y)$ for the period 2069-2099 (dashed box) are respectively -14 and $-9 \%$. b EC-8.5

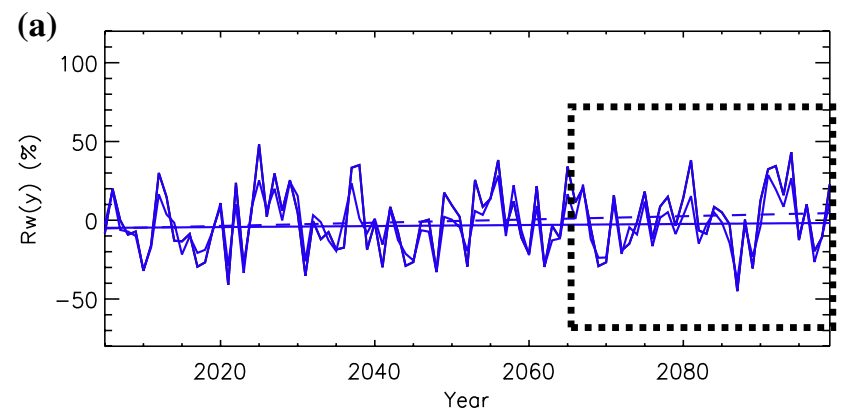

Fig. 14 Functions $R w(y)$ (solid line) and $R w_{\rho}(y)$ (dashed line) plotted with their least squared regressions. a MPI-4.5 simulation, the linear variation coefficients of $R w(y)$ and $R w_{\rho}(y)$ are respectively 0.10 and $0.03 y^{-1}$. The mean values of $R w(y)$ and $R w_{\rho}(y)$ for the period 2069-2099 (dashed box) are respectively 1.68 and $-3.23 \%$. b MPI- changed in the equation. Figure 13 shows the evolution of $R w(y)$ and $R w_{\rho}(y)$ for the EC-4.5 and EC-8.5 simulations. Both functions are also plotted as their least-squared linear regressions.

The mean relative decrease of $R w(y)$ and $R w_{\rho}(y)$ for the period 2069-2099 compares with the relative decrease in overturning circulation at Gotland Deep (BY15), even though it is higher: the decrease in overturning circulation extracted from Nemo-Nordic, reaches $6.5 \%$ for the EC-4.5 run, and $15 \%$ for the EC- 8.5 run. Therefore the figures extracted from the model seem to agree better with the variation of $R w_{\rho}(y)$ than with that of $R w(y)$ which seems to over-estimate the changes.

The same approach has been made for the MPI-4.5 and MPI- 8.5 based simulations. Changes observed in the Nemo-Nordic simulations show a decrease of 5 and $9 \%$ respectively.

If one considers the relative changes of $R w_{\rho}(y)$ for the period 2069-2099, they also fit with the changes observed in the Nemo-Nordic simulations. The relative changes of

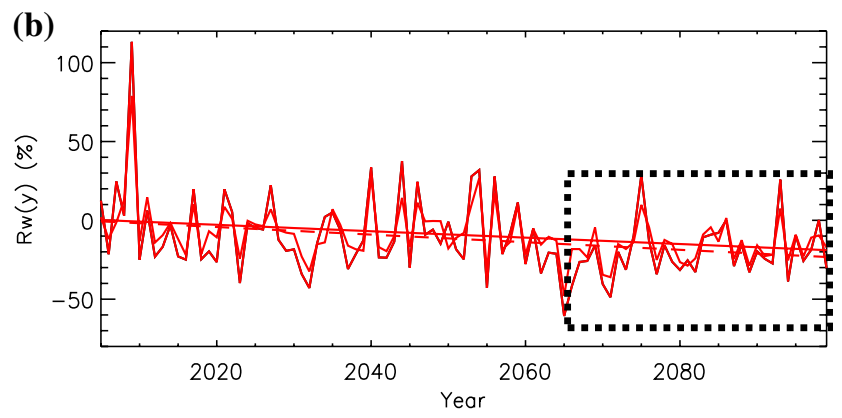

simulation, the linear variation coefficients of $R w(y)$ and $R w_{\rho}(y)$ are respectively -0.24 and $-0.20 y^{-1}$. The mean values of $R w(y)$ and $R w_{\rho}(y)$ for the period 2069-2099 (dashed box) are respectively -19 and $-15 \%$

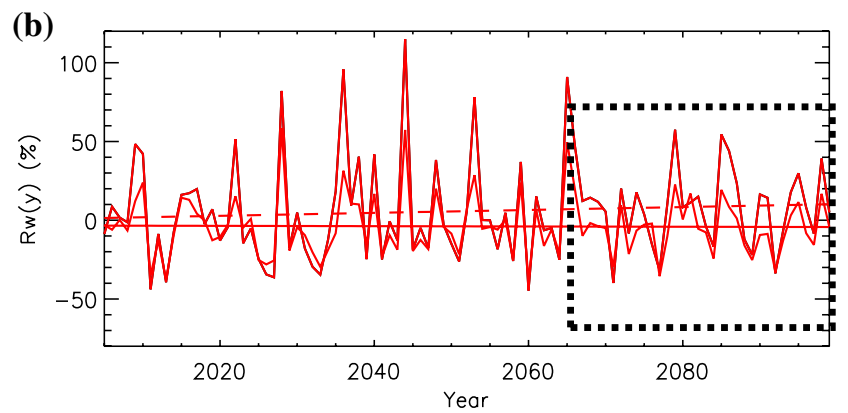

8.5 simulation, the linear variation coefficients of $R w(y)$ and $R w_{\rho}(y)$ are respectively 0.07 and $-0.05 y^{-1}$. The mean values of $R w(y)$ and $R w_{\rho}(y)$ for the period 2069-2099 (dashed box) are respectively 7 and $-5 \%$ 
$R w(y)$ suggest an increase in the overturning circulation (Fig. 14).

\section{Discussion and conclusion}

If one considers only changes in thermal stratification of the model, then the change estimate of entrainment velocity in the thermal mixed layer fits adequately with the changes in overturning circulation.

This occurs when Nemo-Nordic is forced by two climate models, each using two greenhouse gases emission scenarios.

The computation of the entrainment velocity takes into account the net freshwater flux, however this term appears to have a small impact in comparison with the changes of stratification. It is also important to notice that the net freshwater input to the Baltic Sea decreases in the EC-4.5 and EC-8.5 simulations ( -2 and $-3 \%$ respectively). A decrease of the net freshwater input to the Baltic Sea should on the contrary ease the occurency of salt water inflows from a barotropic point of view (Meier et al. 2006), and the overturning circulation. The net freshwater input to the Baltic Sea does not change in the MPI-4.5 simulations and increases by $4 \%$ in the MPI- 8.5 simulations. However, in these simulations one can observe a strong increase of the overturning circulation in the Southern Baltic Sea, especially in the MPI-8.5 simulations, which shows that the increase in the freshwater budget (P-E increases) does not prevent potential salt inflows to enter the Southern Baltic Sea, but that these salt inflows do not penetrate further towards the center of the Baltic Proper and cannot fuel the overturning circulation of the Baltic Sea.

The study made by Schimanke et al. (2014) shows that the intensity of Major Baltic Inflows should increase towards the end of the 21 st century. Their conclusions are based on the analysis of atmospheric patterns in two climate models, forced by two greenhouse gases emission scenarios. In the present study, we use the same atmospheric data as a forcing, but combine it with the use of an ocean model of the Baltic Sea. The concept of "overturning circulation" is a low-frequency perspective of salt water inflows. Salt water inflows are the driver fueling the overturning circulation. We analyze the changes of overturning circulation towards the end of the 21st century by comparing its intensity between two time periods, the first one being for years 1975-2005, the second one being for years 2069-2099. Our findings are opposite to that of Schimanke et al. (2014): we conclude that the overturning circulation of the Baltic Sea is going to decrease by up to $15 \%$ towards the end of the 21st century. This is true for the main basin of the Baltic Sea, the Baltic Proper. It is also true for the other basins such as the Bothnian Sea and the Bothnian
Bay: although smaller in absolute value, this decrease is even higher in relative value (more than $20 \%$ ).

The decrease of the overturning circulation follows a trend which strengthen with the greenhouse gases scenarios and the temperature increase: a higher decrease in overturning circulation can be observed when RCP 8.5 emission scenarios are used, regardless of the climate model that is used to provide the atmospheric forcing. In our simulations, the runoff data that is used is a climatological runoff, which does not change for any year of the simulation. Moreover, the net freshwater input to the Baltic Sea (Runoff plus Precipitation minus Evaporation) decreases in the EC-EARTH forced simulations, and does not increase significantly in the MPI forced simulations. Either the runoff changes should increase salt water inflows, or should at least not affect them significantly from a barotropic point of view. This means that the decrease of the overturning circulation is not related with the changes in net freshwater input to the Baltic Sea, nor is this decrease related with changes in wind patterns, which should increase the overturning circulation. Too much mixing in the Southern Baltic could also reduce deep salt inflows (Meier 2005), but we notice a slight decrease of wind speed for the ECEARTH forced scenarios ( -1.85 and $-0.8 \%$ for EC- 4.5 and EC-8.5 respectively). For the case of the MPI scenarios, a slight increase can be noticed (1.83 and 3.73\% for MPI-4.5 and MPI-8.5 respectively), but which is far less than that required to impact deep salt inflows according to Meier (2005). The decrease of overturning circulation could be related with a change of wind strength or variability, especially if one considers upwelling dynamics as an important element of the overturning circulation. A decrease of wind strength and/or variability could affect Baltic Sea upwellings. A couple of studies investigated potential future changes of wind characteristics (average speed, gustiness, direction) over the Baltic Sea (NIKULIN et al. 2011; Gräwe et al. 2013; Junjie et al. 2015). All of these studies conclude either that wind characteristics do not change (Junjie et al. 2015) or they state very carefully that there might be a small increase in wind speed/gustiness (NIKULIN et al. 2011; Gräwe et al. 2013). To our knowledge, no study claims that the wind speed will decrease in the future. Hence, we did not investigate this possibility: we concluded that the documented changes of the overturning circulation are the result of a change in thermohaline circulation.

Our analysis based on the theory of Stigebrandt (1985) shows that the relative changes of entrainment velocity are close to that of overturning circulation as far as the Baltic Proper is considered. It also strongly suggests that the modeled changes in overturning circulation are related with an increase of thermal stratification at the level of the mixed layer. This increase contributes to a stronger shielding of the erosion of the permanent halocline of the Baltic Sea. 
If wind effects are not directly considered in the theory of Stigebrandt (1985), then the trend of decrease of the entrainment velocity within the layer in which thermal stratification changes occur correlate with the changes of overturning circulation in the center of the Baltic Proper. For the EC-EARTH forced runs, using this theory at the center of the Baltic Proper predicts a change of -9 and $-15 \%$ of the entrainment velocity caused by increased thermal stratification, for EC-4.5 and EC-8.5 scenarios respectively. The model itself predicts a change of respectively -6.5 and $-15 \%$ respectively. In the case of the MPI forced runs, the theory predicts a change of -3 and $-6 \%$ which is very close to what the model gives $(-5$ and $-8 \%$ respectively). The theory contradicts with the model predictions if wind changes are used directly in the theory: the theory then overestimates the changes when it comes to the EC-EARTH forced simulations and predicts an increase of overturning circulation which is contrary to model predictions for the MPI forced simulations.

It should be noted that the model does predict an increase of overturning circulation in the Southern Baltic Sea for this latest case, but this could be related with an increase of wind-forced potential salt inflows, which however do not penetrate any further in the Baltic Proper.

However, neglecting the wind changes for the computation of friction velocity according to the theory of Stigebrandt (1985) does not mean that changes in wind stress are not taken into account: wind stress has an impact on mixed layer stratification within the model, which forms the basis of our computation. The discrepancy of results when changes in wind stress are directly taken into account in the theory. A possible explanation could reside into the fact that the theory of Stigebrandt (1985) uses a third power of the friction velocity which makes it extremely sensitive to any inaccuracy due to the approximation that the Gotland Deep (BY15) profile is used as a proxy for the entire Baltic Proper.

Our analysis predicts that the increase of thermal stratification in sill estuaries such as the Baltic Sea and the Black Sea, will decrease the overturning circulation, meaning the amount of the salty water masses that penetrate the deepest parts of the estuary and fuel what Döös et al. (2004) described as a "haline conveyor belt". Since our approach provides a time integrated view of the problem, it is impossible to tell how the strength and variability of the Baltic Sea MBIs will be affected: will there be less MBIs with a smaller amplitude, or less MBIs with a larger amplitude, or more MBIs but with a much smaller amplitude. The question remains open. Since the ecosystem is usually more sensitive to extreme values more than changes in mean values (lower salinity or oxygen extremes for example), this question should also be answered but is left to further investigation.
Acknowledgements This work was part of the projects BONUS Stormwinds and BONUS BIO-C3, funded jointly by BONUS (Art 185 ) and the Swedish Research Council for Environment, Agriculture Sciences and Spatial Planning (FORMAS, grants no 292985 and no 219-2013-2041). This work is also funded by the SmartSea project of the Strategic Research Council of Academy of Finland, grant No: 292 985. The authors wish to thank the editor and the anonymous reviewers who helped improve this manuscript.

Open Access This article is distributed under the terms of the Creative Commons Attribution 4.0 International License (http:// creativecommons.org/licenses/by/4.0/), which permits unrestricted use, distribution, and reproduction in any medium, provided you give appropriate credit to the original author(s) and the source, provide a link to the Creative Commons license, and indicate if changes were made.

\section{References}

Döös K, Meier M, Döscher R (2004) The baltic haline conveyor belt or the overturning circulation and mixing in the baltic. Ambio 33. doi:10.1357/002224006777606506

Fong D, Geyer W (2002) The alongshore transport of freshwater in a surface-trapped river plume. J Phys Oceanogr 32:957-972

Funkquist L, Kleine E (2007) Hiromb — an introduction to hiromb, an operational baroclinic model for the baltic sea. Tech. rep, SMHI

Garvine RW, Whitney MM (2006) An estuarine box model of freshwater delivery to the coastal ocean for use in climate models. J Mar Res 64(2):173-194. doi:10.1357/002224006777606506

Gräwe U, Friedland R, Burchard H (2013) The future of the western baltic sea: two possible scenarios. Ocean Dyn 63(8):901-921. doi:10.1007/s10236-013-0634-0

Hordoir R, Axell L, Löptien U, Dietze H, Kuznetsov I (2015) Influence of sea level rise on the dynamics of salt inflows in the baltic sea. J Geophys Res Oceans. doi:10.1002/2014JC010642

Hordoir R, Dieterich C, Basu C, Dietze H, Meier M (2013) Freshwater outflow of the baltic sea and transport in the norwegian current: A statistical correlation analysis based on a numerical experiment. Contin Shelf Res 64:1-9. doi:10.1016/j. csr.2013.05.006

Hordoir R, Meier M (2011) Effect of climate change on the thermal stratification of the baltic sea: a sensitivity experiment. Clim Dyn 38:1703-1713. doi:10.1007/s00382-011-1036-y

Hordoir R, Nguyen K, Polcher J (2006) Simulating tropical river plumes. A set of parametrizations based on macroscale data, a test case in the Mekong delta region. J Geophys Res 111:392. doi:10.1029/2005JC003

Hordoir R, Polcher J, Brun-Cottan JC, Madec G (2008) Towards a parametrization of river discharges into ocean general circulation models: a closure through energy conservation. Clim Dyn 31 . doi:10.1007/s00382-008-0416-4

Junjie D, Jan H, Semjon S, Markus MHE (2015) ohs, vol. 44, chap. A method for assessing the coastline recession due to the sea level rise by assuming stationary wind-wave climate. doi:10.1515/ ohs-2015-0035. http://www.degruyter.com/view/j/ohs.2015.44. issue-3/ohs-2015-0035/ohs-2015-0035.xml, p 3623

Madec G (2015) The NEMO system team: Nemo ocean engine, version 3.6 stable. Tech. rep., IPSL. http://www.nemo-ocean.eu/. Note du Pôle de modélisation de l'Institut Pierre-Simon Laplace No. 27

Matthäus W (2006) The history of investigation of salt water inflows in the baltic sea-from the early beginning to recent results. Tech. rep, Baltic Sea Research Institute, IOW 
Meier H, Hordoir R, Andersson H, Dieterich C, Eilola K, Gustafsson B, Höglund A, Schimanke S (2012) Modeling the combined impact of changing climate and changing nutrient loads on the baltic sea environment in an ensemble of transient simulations for 1961-2099. Clim Dyn 39(9-10):2421-2441. doi:10.1007/ s00382-012-1339-7

Meier H, Kauker F (2002) Simulating Baltic sea climate for the period 1902-1998 with the rossby centre coupled ice-ocean model. Tech. rep., SMHI. Report Oceanography No. 30

Meier HEM (2005) Modeling the age of Baltic Sea water masses: quantification and steady state sensitivity experiments. J Geophys Res 110: C02,006. doi:10.1029/2004JC002 (607)

Meier HEM, Kjellström E, Graham LP (2006) Estimating uncertainties of projected baltic sea salinity in the late 21 st century. Geophys Res Lett. doi:10.1029/2006GL026488

Nikulin G, Kjellstrm E, Hansson U, Strandberg G, Ullerstig A (2011) Evaluation and future projections of temperature, precipitation and wind extremes over europe in an ensemble of regional climate simulations. Tellus A 63(1):41-55. doi:10.1111/j.1600-0870.2010.00466.x

Samuelsson P, Jones CG, Willén U, Ullerstig A, Gollvik S, Hansson U, Jansson C, Kjellström E, Nikulin G, Wyser K (2011) The rossby centre regional climate model rca3: model description and performance. Tellus A 63(1):4-23. doi:10.1111/j.1600-0870.2010.00478.x

Schimanke S, Dieterich C, Meier HEM (2014) An algorithm based on sea-level pressure fluctuations to identify major baltic inflow events. Tellus A 66. http://www.tellusa.net/index.php/tellusa/ article/view/23452

Stigebrandt A (1985) A model for the seasonal pycnocline in rotating systems with application to the baltic proper. J Phys Oceanogr 15(11):1392-1404 